\title{
Effect of Dam Construction on Vegetation Cover and Shoreline: A case study
}

\author{
Shivangi Mishra ${ }^{1}$, Priyanka Dhurvey ${ }^{2}$, Subha Sinha ${ }^{3 *}$, Pallav Kumar ${ }^{4}$ \\ 1,3,4 Assistant Professor, MIT Muzaffarpur, Muzaffarpur - 842003, India. \\ ${ }^{2}$ Assistant Professor, MANIT Bhopal - 462003, Madhya Pradesh, India.
}

\begin{abstract}
Geographical Information System (GIS) as a tool for environmental impact assessment (EIA) has gained the interest of researchers in the last two decades. The present research is aimed at studying the effect of dam construction on vegetation cover and dam shoreline under two scenarios: (b) before-andafter dam construction and (a) three consecutive years after dam construction, using GIS. With this motivation, dam under construction on Lower Subansiri river is considered for the research. To discern the changes before dam construction, images are obtained using Landsat 4, for the year (1999) before dam construction. However, Landsat 7 is used for obtaining the change in trend of vegetation and dam shoreline over the years from 2009 to 2011, after dam construction. Normalized Difference Vegetation Index (NDVI) and Normalized Difference Water Index (NDWI) are calculated for different years using Red-Green-Blue (RGB) bands and Near-Infra-Red (NIR). It is observed that there is substantial decrement in vegetation cover and significant increment in dam shore line due to the construction of dam. The decrement in the vegetation cover over three consecutive years are found to be $35 \%$ and $80 \%$ and increment in dam shoreline are found to be $17 \%$ and $33 \%$, taking first year as base among three consecutive years, with area under consideration of $30 * 30 \mathrm{~km}^{2}$. The approach given in the present study can be useful in quantifying the changes in vegetation cover and dam shore line over the years, using GIS. The results may be helpful in predicting any chances of danger or hazard to the environment for such projects.
\end{abstract}

Keywords- Normalized Difference Vegetation Index (NDVI), Normalized Difference Water Index (NDWI), Remote Sensing, GIS.

\section{INTRODUCTION}

GIS as a tool is having a wide range of application in different area of research. Specifically, in the field of Civil Engineering, it has become a potential tool for usage in different stages of Environmental Impact Assessment (EIA). It has an integrative framework which can be classified into different steps. The major steps in the entire framework are; generation, storage, and display of the thematic information related to the vulnerability/sensitivity of the affected resources. The impact prediction of any affected resources can be done with various evaluation tool, which will be helpful in decision support. From analytical perspective, there are several purposes for which GIS is used in EIA. Some of them are; data management, overlay analysis and trend analysis. The other purposes it can serve is to act as sources of data sets for mathematical impact models, habitat and aesthetic analysis, for public consultation. Recently, the use of GIS in EIA has increased extensively for the purpose of data preparation, analysis/modeling and generating results in computational analysis. GIS have also been used for the presentation of environmental baseline information and project description, through the preparation of thematic maps for the several environmental descriptors. Also, the overlay of baseline information maps with project layouts is frequently used for impact identification. GIS also enable the use of a set of simple operations such as overlay, classification, interpolation, aggregation of spatial information that can generate additional information to support impact prediction. The overview on application of GIS as a tool in different fields developed the interest of authors to further use this tool in impact assessment of dam construction on vegetation cover and dam shoreline areas around the Lower Subansiri river.

\section{LITERATURE REVIEW}

A review of literatures conducted towards use of GIS as a tool for environmental impact assessment for different projects is given here. Sahin and Kurum (2002) assessed the impact of dam constructions on the areas having higher landscape value using GIS for Seyhan Kopru Hydroelectric Dam project. Amdihun (2008) made an attempt to study the environmental impacts of Finchaa irrigation project using GIS and remote sensing techniques. The parameters such as natural environment, soil/land and water quality were considered in the study. Normalized vegetation index (NDVI) was used as basis to identify the spatial and temporal change of vegetation biomass in the study area. For discerning the changes, the satellite images of different years were used in the study. This helped in identification of the vegetation cover with the expansion of the irrigation in Finchaa valley. In another study by Adel and Ryutaro (2007), maximum likelihood supervised classification and post-classification change detection techniques were applied to Landsat images, for the images which were obtained different years. The years selected for the study were 1987 and 2001 to map land cover changes in the Northwestern coast of Egypt. A supervised classification technique was employed to obtain the six reflective bands for the two images separately. Another study by Yaw et al. (2003) put an emphasis on assessment of negative impacts of Volta 
International Journal of Engineering Research and Technology. ISSN 0974-3154, Volume 13, Number 7 (2020), pp. 1686-1691

(C) International Research Publication House. https://dx.doi.org/10.37624/IJERT/13.7.2020.1686-1691

River Project, Ghana using remote sensing as a tool to ascertain the impacts. The study further obtained Landsat Thematic Mapper (TM) and Enhanced Thematic Mapper (ETM+) floating scenes of May 1985 and June 2000 from the United State Geological Survey (USGS) Department. The study area was then subseted using Erdas Imagine subset tool. Jain et al. (2002) proposed an index-based approach, which is based on the factors responsible for soil erosion. The factors considered are; soil type, vegetation, slope and catchment properties such as drainage density and form factor. A case study is made to illustrate the approach, where catchment area was selected immediately upstream of the Ukai Reservoir located on the River Tapi in Gujarat State, India. The combined effects of parameters are evaluated to find different areas vulnerable to soil erosion. Based on the study, two watersheds were identified as most susceptible to soil erosion. Integrated index was used as basis and recommended to provide a priority rating of the watersheds for soil conservation planning. Dewan et al. (2009) studied the changes in land use/cover changes and urban sprawl for Greater Dhaka, Bangladesh. The evaluation of changes in the just-mentioned attributes were made between 1975 and 2003 considering satellite images and socioeconomic data. The spatial and temporal changes in land use/cover changes were quantified using three Landsat images. Moreover, a supervised classification algorithm was made using change detection algorithm in GIS. The accuracy of the Landsat-derived land use/cover maps ranged from 85 to $90 \%$. It was attributed based on analysis that significant growth of built-up areas in Greater Dhaka for the period of study has resulted into considerable decrease in water bodies, cultivated land, vegetation and wetlands. The expansion of urban land has been largely due to change in elevation, exponential population growth and higher level of economic development. The study also concluded that the rapid expansion in urban area through infilling of low-lying areas and clearing of vegetation cover has created negative impact on environments and habitat quality. Rokni et al. (2014) conducted a case study on Lake Urmia during the period of 2000 to 2013. This case study was done with a motive to model the spatio-temporal changes in Lake Urmia. To fulfill the objective multi-temporal images were collected from Landsat 5-TM, 7-ETM+ and 8-OLI images. While doing so, different satellite-derived indices such as NDWI, MNDWI, NDMI, WRI, NDVI, and AWEI were investigated for the extraction of surface water from Landsat data. Among the different indices, NDWI was found performing better compared to other indexes. Therefore, it was used as basis to model the spatiotemporal changes in the lake. Additionally, a new approach was proposed, which is based on Principal Components of multi-temporal NDWI (NDWIPCs). Further, it was evaluated for identification of change detection in surface water. Hegazy et al. (2015) made an attempt to assess land use changes using GIS. The case study was conducted in Mansoura and Talkha for the time period of 1985 to 2010. An analysis on change detection for built-up area was made. The change in built-up area was found to have increased significantly over the year, from 28 to $255 \mathrm{~km}^{2}$, however, agricultural land has reduced significantly. Based on the time series data of changes, future prediction is done by using the Markov chain analysis.

With the background and motivation from previous literatures, the present study is conducted with primary objective to assess the effect of dam construction on vegetation growth and dam shoreline for Lower Subansiri river, in Assam.

\section{STUDY AREA}

The Subansiri Lower Dam is officially named Lower Subansiri Hydroelectric Power Project (LSHEP), is a gravity dam on the Subansiri River in northeastern India. This project is located at $2.3 \mathrm{~km}$ upstream of Gerukamukh village in Dhemaji district and Lower Subansiri district on the border of Assam and Arunachal Pradesh states. The project has aquired 3180 ha area of land, including $1333 \mathrm{Ha}$ forest land, and 2867 ha area under submergence. As forest area is greatly affected, there is an impact caused on the flora and fauna of the area. The species are facing trouble by permanent increase in the water turbidity as an outcome of the dam construction. The excavation works has caused changes in the streambed structures which in turn has affected the creatures living there negatively; even resulted in their death.

\section{MATERIAL AND METHODS}

The steps involved for analysis are given below:

1. Images have been taken from glovis (glovis.usgs.gov) and cropped around the dam location in size of $(402 \times 402)$ pixels, resolution in $30 \mathrm{~km}$. Images for the year 1999 and 2010 have been taken for change detection. This collection includes images from Landsat $4 \mathrm{TM}$ and Landsat 7, respectively for the years just mentioned. All the Landsat sensors utilize World Reference System-2 (WRS-2). From the website, Red, Green, Blue (RGB) Band and NonInfrared (NIR) images were obtained. Landsat 7 data is used for three years; 2009, 2010 and 2011.

2. Images which have been used were not aligned in the same coordinate system since they were obtained from two different sources as Landsat 4 and Landsat 7. The alignment process is done using "i2k Align software.

3. Once the images were aligned, it was given as input to MATLAB software and their DN number were generated. Later, using those DN numbers, NDWI and NDVI were calculated using the formula given in successive two steps.

4. Normalized Difference Water Index (NDWI) was developed for the extraction of water features from Landsat imagery. It can be calculated as:

$$
N D W I=(\text { Green }-N I R) /(\text { Green }+ \text { NIR })
$$

5. The normalized difference vegetation index (NDVI) is a simple graphical indicator that can be used to analyze remote sensing measurements, typically but not necessarily from a space platform, and assess whether the target being observed contains live green vegetation or not. It can be calculated as:

$$
N D V I=(N I R-R e d) /(N I R+R e d)
$$

6. The logical images of NDWI and NDVI were obtained 
using MATLAB coding. The values of NDWI and NDVI which were smaller than 0 were designated as ' 0 ' showing no change in the vegetation or dam shoreline. However, the values greater than 0 were designated as ' 1 ' showing the change in the vegetation or dam shoreline. For this purpose, 'XOR' operation of coding language was used.

\section{RESULTS AND ANALYSIS}

This section has three parts of analysis:

(i) Analysis of images before dam construction

(ii) Analysis of images after dam construction

(iii) Changes in vegetation cover and dam shoreline for three consecutive years

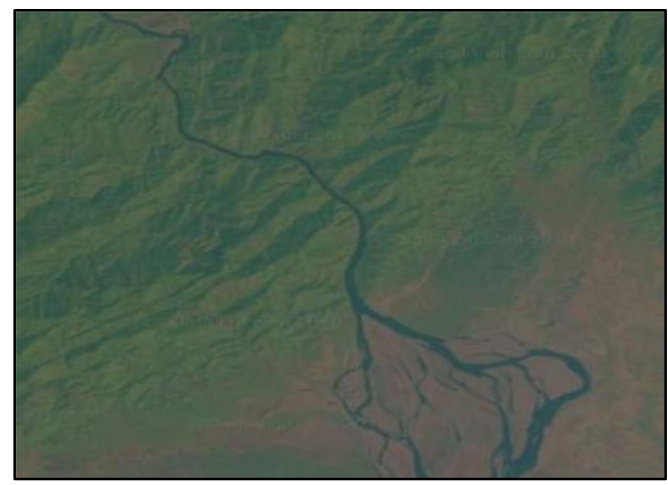

Fig 1.RGB image for year 1999

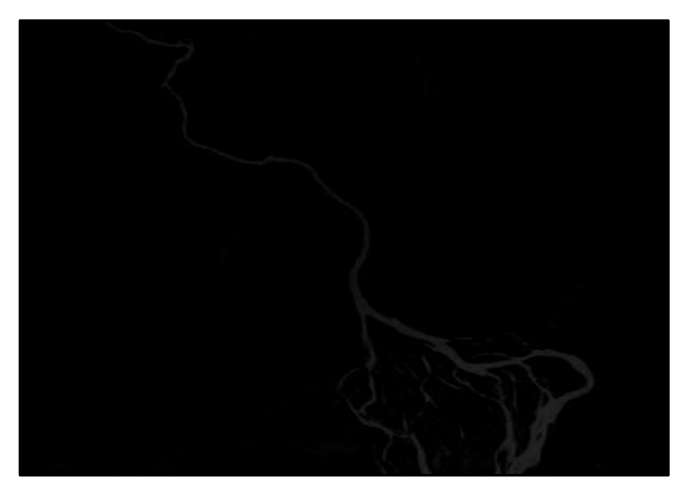

Fig 3. NDWI image for year 1999

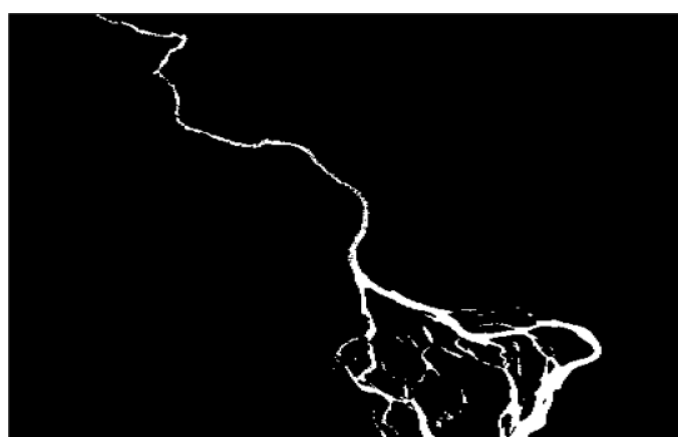

Fig 5. NDVI image for year 1999
In the subsequent subsections, the aforementioned three analysis are provided:

\section{Analysis of Images for the Year Before Dam Construction: 1999}

The six steps shown in methodology section were followed for the year when dam was not constructed. Figure 1 to Figure 6 depicts the images obtained through different steps of methodology. The images directly obtained from the website are shown in Figure 1 and Figure 2. NDWI image and NDWI logical images are shown in Figure 3 and Figure 4. The logical images show the places where watershed along the dam shoreline is affected positively or negatively based on code generated. Similarly, NDVI image and NDVI logical images are shown in Figure 5 and Figure 6.

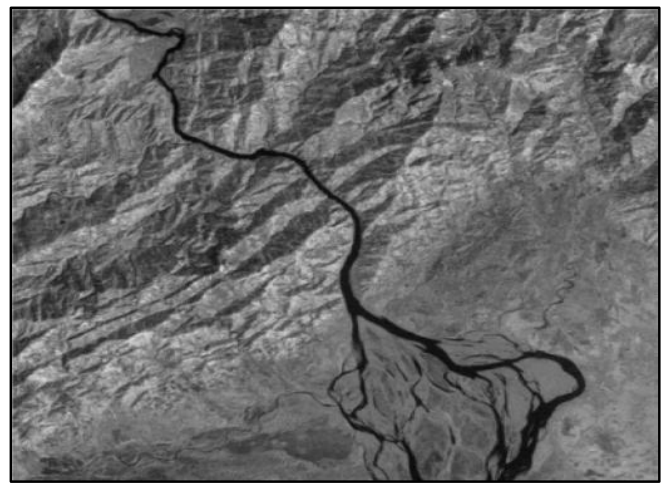

Fig 2.NIR image for year 1999

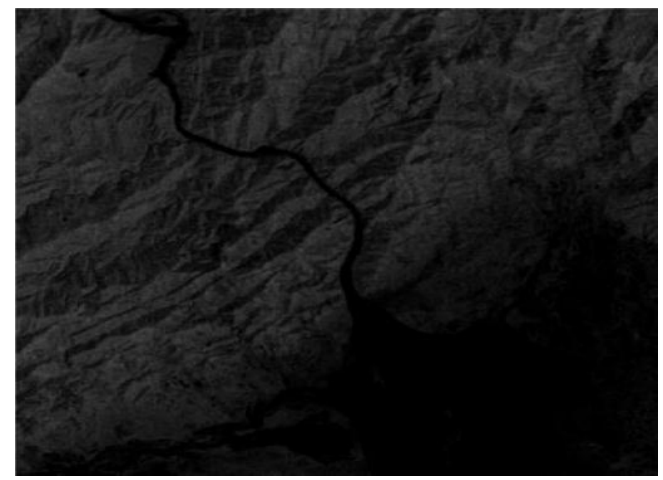

Fig 4. NDWI logical image for year 1999

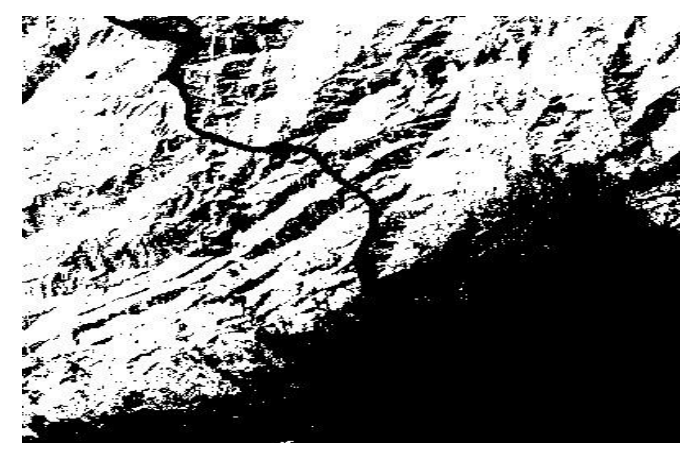

Fig 6. NDVI logical image for year 1999 
Analysis of Images for the Year after Dam Construction: 2010

Similar procedure as shown in previous section was applied for the year 2010, just after dam construction. Figure 7 and Figure 8 shows the RBG image of Subansiri Dam and NIR image of Subansiri Dam, respectively, obtained from website, as explained in methodology section. Figure 9 and 10 shows the NDWI image and NDWI logical images whereas; Figure 11

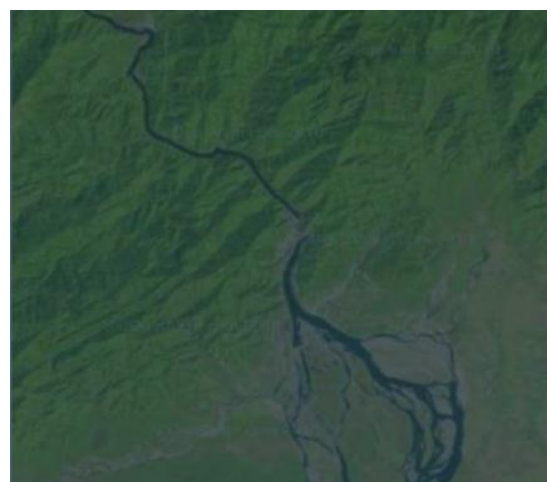

Fig. 7 RGB image for year 2010

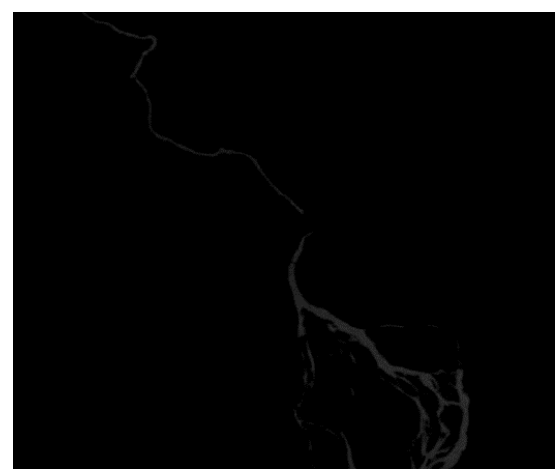

Fig 9. NDWI image for year 2010

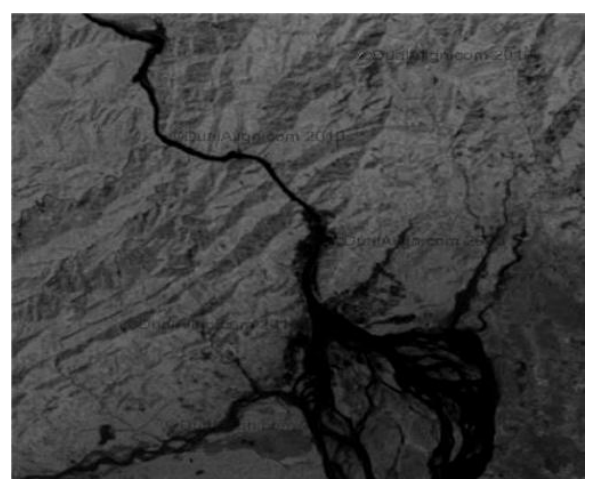

Fig 11. NDVI image for year 2010 and 12 represents the NDVI and NDVI logical images.

The map of the changes in the dam shoreline and vegetation before and after construction of dam is shown in Figure 13 and Figure 14, respectively. From Figure 13, it is observed that dam shoreline has increased at different places but also, at some places, there are decrements observed. However, in case of vegetation, as shown in Figure 14, there is considerable decrement in growth.

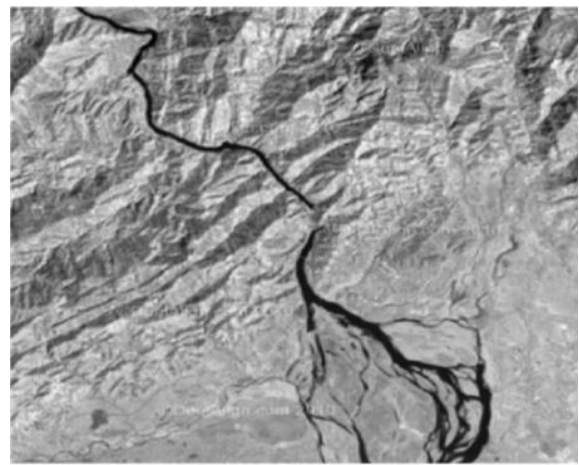

Fig 8.NIR image for year 2010

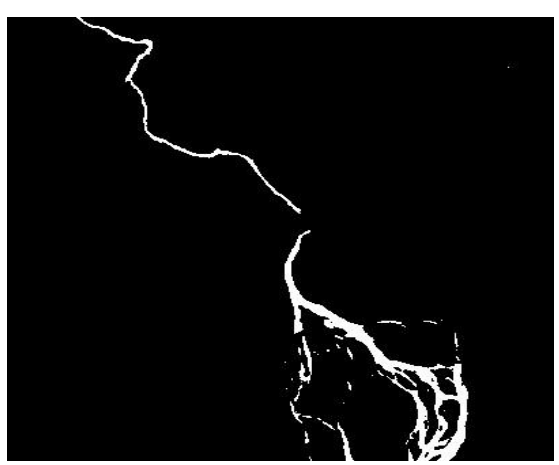

Fig 10. NDWI logical image for year 2010

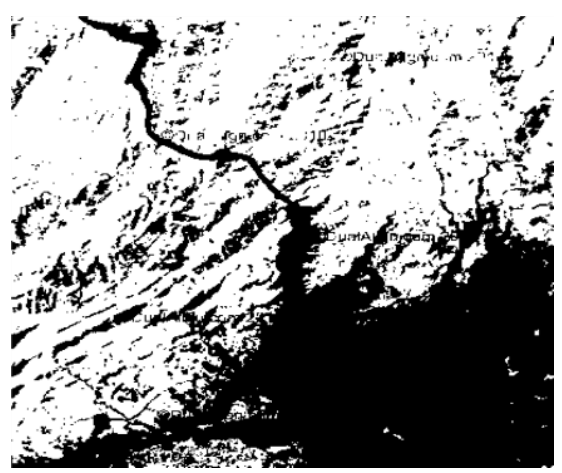

Fig 12. NDVI logical image for year 2010 


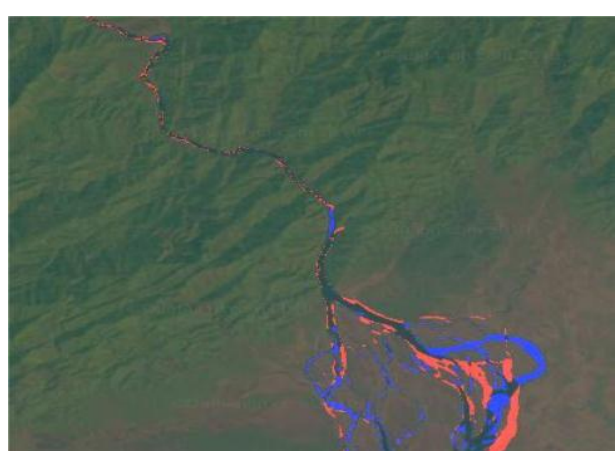

Increment in dam shoreline

Decrement in dam shoreline

Fig 13. Changes in dam shoreline (1999-2010)

\section{Changes in Vegetation Cover and Dam Shoreline over the Years}

To understand the changes in vegetation cover and dam shoreline over the years, the logical images were obtained for three consecutive years; 2009, 2010 and 2011. Based on the logical images, the area values are calculated using number of pixels for the entire area of $30 * 30 \mathrm{~km}^{2}$ taken into consideration for the present study. The changes in dam shore line over the years are depicted in Figure 15 and area affected are shown in Table 1 . The changes can be easily observed through Figure 15 for different years. Moreover, if 2009 is considered as base year, as shown in Table 1, the change in dam shoreline in found to be have increased by $17 \%$ (in terms of area) for the year 2010 and $33 \%$ (in terms of area) for the year 2011, which is considerably high.
2009

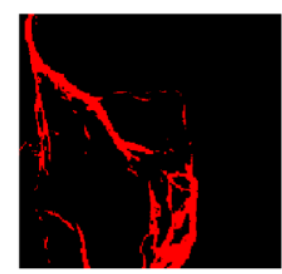

2010

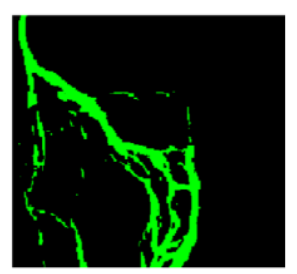

2011

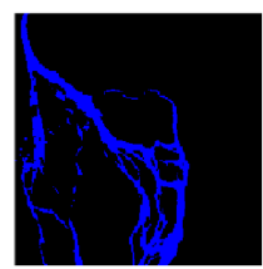

Fig 15. Change in Dam Shoreline Logical images from 2009 to 2011

Table 1. Change in Area of Dam Shore line from year 2009 to 2011

\begin{tabular}{|l|c|c|c|c|}
\hline Year & \multirow{2}{*}{$\begin{array}{c}\text { Dam Shoreline } \\
\left(\text { meter }^{2}\right)\end{array}$} & \multicolumn{3}{|c|}{$\begin{array}{c}\text { Change in surface Area } \\
\left(\text { meter }^{2}\right)\end{array}$} \\
\hline 2009 & 93240 & & - & \\
\cline { 1 - 1 }+2010 & 109200 & +16000 & +15090 & \\
\hline 2011 & 124290 & - & +31090 \\
\hline
\end{tabular}

On similar lines, analysis is carried out for change in logical

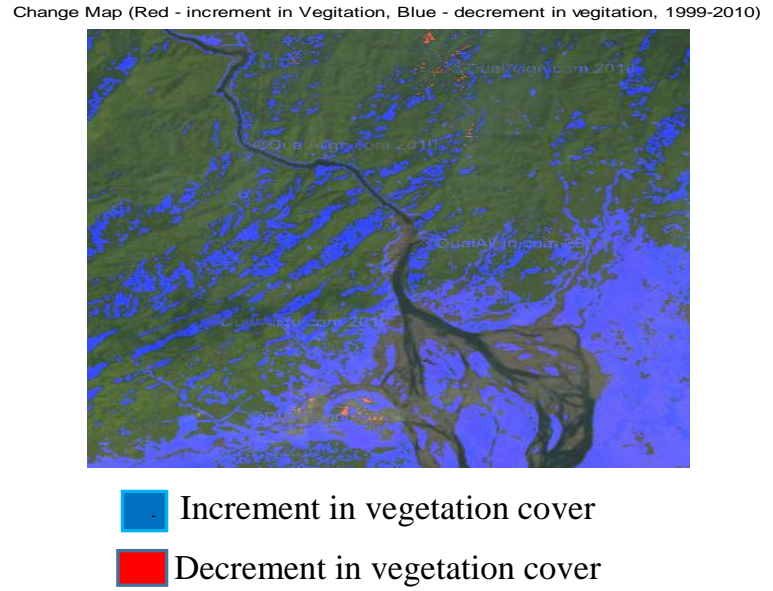

Fig 14. Changes in vegetation cover (1999-2010)

images of vegetation cover from year 2009 to 2011. The changes are depicted in Figure 16 and Table 2. It can be clearly identified from Figure 16 that the vegetation cover has been considerably decreased due to the construction of dam over the years. To quantify this effect in terms of area of vegetation cove, area of vegetation cover was obtained based on the pixels of the logical images generated. If 2009 is considered as base year, the area of vegetation cover is reduced by $35 \%$ and $80 \%$ respectively for the overall area of $30 * 30 \mathrm{~km}^{2}$ taken into consideration. This clearly shows that vegetation cover is substantially affected due to construction of dam over the years.

Table 2. Change in Area of Vegetation Cover from year 2009 to 2011

\begin{tabular}{|l|c|c|c|c|}
\hline Year & $\begin{array}{c}\text { Vegetation } \\
\text { Cover }\left(\text { meter }^{2}\right)\end{array}$ & \multicolumn{2}{|c|}{$\begin{array}{c}\text { Change in Surface } \\
\left(\text { meter }^{2}\right)\end{array}$} \\
\hline 2009 & 96060 & \multirow{2}{*}{-34140} & - & \\
\cline { 1 - 2 } 2010 & 61920 & & -47580 & -740 \\
2011 & 18480 & - & & \\
\hline
\end{tabular}

2009
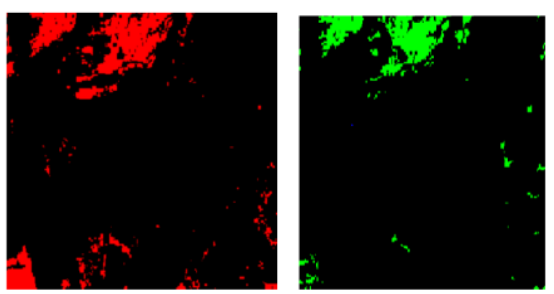

Fig 16. Change in Vegetation Cover from 2009 to 2011 
International Journal of Engineering Research and Technology. ISSN 0974-3154, Volume 13, Number 7 (2020), pp. 1686-1691

(C) International Research Publication House. https://dx.doi.org/10.37624/IJERT/13.7.2020.1686-1691

\section{CONCLUSION}

GIS has become a tool of great importance for analyzing the trends of images of change in natural slopes of river, vegetation cover, flood prediction, mitigation measures, and so on. Considering the usefulness of this tool, present study is focused on change detection due to dam construction at Lower Subansiri dam in Assam. The changes in vegetation cover and shoreline of Lower Subansiri river, before and after the construction of dam is assessed using images from satellite data in GIS. Based on the changes in images over the years, NDVI and NDWI are calculated to identify the effect of dam construction on vegetation and dam shoreline. The changes in the images shows a significant impact due to dam construction on the area of $30 * 30 \mathrm{~km}^{2}$ under consideration in the present study. The effect on vegetation and dam shoreline is calculated for three consecutive years; 2009, 2010 and 2011. The analysis showed significant increase in dam shoreline area and significant decrease in vegetation growth due to construction of dam. The increment in dam shoreline were found to be $17 \%$ and 33\%, respectively for years 2010 and 2011, when compared with year 2009 for $30 * 30 \mathrm{~m}^{2}$ area considered in the present study. Similarly, the decrement in vegetation growth are found to be $35 \%$ and $80 \%$, for the years 2010 and 2011 comparing with year 2009, which is also substantially high. The steps and approach of image analysis presented in the study can be useful in examining environment impact assessment for similar kind of projects.

\section{REFERENCES}

[1] Amdihun,A. "GIS and Remote Sensing Integrated Environmental Impact Assessment of Irrigation Project in Finchaa Valley Area", Impact of Irrigation on Poverty and Environment in Ethiopia, Draft Proceeding of the symposium and exhibition, Ethiopia, pp. 400-417, 2008.

[2] Adel, S. and Ryutaro, T. "Remote sensing and GIS for mapping and monitoring land cover and land-use changes in the Northwestern coastal zone of Egypt", Applied Geography, Vol. 27, Issue 1, pp 28-41, 2007.

[3] Dewan A.M., Yamaguchi Y., "Using remote sensing and GIS to detect and monitor land use and land cover change in Dhaka Metropolitan of Bangladesh during 1960-2005", Environmental Monitoring and Assessment, 150, pp. 237-249, 2009.

[4] Hegazy, I.R., Kaloop, M.R. "Monitoring urban growth and land use change detection with GIS and remote sensing techniques in Daqahlia governorate Egypt", International Journal of Sustainable Built Environment, Vol. 4, pp. 117-124, February 2015.

[5] Jain S.K., Goel, M. K., "Assessing the Vulnerability to Soil Erosion of the Ukai Dam Catchments using Remote Sensing and GIS", Hydrological Sciences Journal, Vol. 47, Issue 1, pp. 31-40, February 2002.

[6] Rokni K., Ahmad A., Selamat A., Hazini S., "Water Feature Extraction and Change Detection using Multitemporal Landsat Imagery", Remote Sensing, Vol.
6, Issue: 5, pp. 4173-89, May 2014.

[7] Sahin S. and Kurum E., "Erosion risk analysis by GIS in environmental impact assessments: a case study Seyhan Kopru Dam construction", Journal of Environmental Management, Vol 66, pp. 239-247, 2002.

[8] Yaw, T.A., Andrew, M., Tommy, C.M. "Management of Watersheds with Landsat TM Data: A Case Study of the Volta River in Ghana", Geoscience and Remote Sensing Symposium, IEEE International, Vol. 2, pp. 1004-1006, 2003. 